\title{
Quality of Life Among HIV Positive Individuals in Kathmandu Valley and Eastern Region of Nepal
}

\author{
Agrawal $\mathrm{H}^{1}$ Mourya $\mathrm{R},{ }^{1}$ Shrestha RK, ${ }^{2}$ Agrawal $\mathrm{S}^{3}$
}

\author{
${ }^{1}$ MBBS Final Year Student \\ ${ }^{2}$ Department of Medicine \\ ${ }^{3}$ Department of Dermatology \& Venereology \\ B. P. Koirala Institute of Health Sciences, \\ Dharan Nepal
}

\section{Corresponding Author}

Sudha Agrawal

Department of Dermatology and Venereology

B. P. Koirala Institute of Health Sciences

Dharan, Nepal

E-mail: sudha92@yahoo.com

Citation

Agrawal H, Mourya R, Shrestha RK, Agrawal S. Quality of life among HIV positive individuals in Kathmandu Valley and Eastern Region of Nepal. Kathmandu Univ Med J 2012;10(4):3-7.

\begin{abstract}
Background

The alarming increase of HIV/AIDS, inability to afford highly active anti-retroviral therapy, disability and stigma associated with the disease, loss of productivity due to illness, and chronic nature of the disease has made HIV/AIDS one of the most important public health problems in developing countries. The Quality of life assessment is focused on humanistic element and intervention resulting from this result may lead to better overall patient well being.
\end{abstract}

\section{Objective}

The aim of our study was to assess and compare the quality of life among HIV positive individuals in Kathmandu Valley \& Eastern region.

\section{Methods}

The study was conducted among 228 HIV positive individuals from Eastern Nepal and 213 from Kathmandu valley and they were compared with an equal number of age-sex matched controls from the community. The instrument used was the WHO QOL-BREF Nepali questionnaire.

\section{Results}

The HIV positive individuals had significantly lower $(P<0.001)$ QOL scores than the controls in the overall QOL and all the domains of life: Physical, Psychological, Social and Environmental. HIV positive individuals from Kathmandu valley scored significantly better $(\mathrm{P}<0.001)$ scores in the Physical and Environmental domains when compared to HIV positive individuals from Eastern region. HIV positive females had a significantly higher $(\mathrm{P}<0.02) \mathrm{QOL}$ scores for overall QOL and overall perception of health than the males.

\section{Conclusion}

These findings suggest that HIV positive individuals have a poorer quality of life than the general population in Kathmandu valley \& Eastern region of Nepal and interventions could be targeted to improve this aspect of their health.

\section{KEY WORDS}

HIV/AIDS, QOL, NEPAL, WHO QOL-BREF

\section{INTRODUCTION}

The UNAIDS estimated 39.5 million people worldwide are infected with HIV, with 75,000 people in Nepal. ${ }^{1,2}$ The alarming increase of HIV/AIDS, inability to afford highly active anti-retroviral therapy, disability and stigma associated with the disease, loss of productivity due to illness, and chronic nature of the disease has made HIV/ AIDS one of the most important public health problems in developing countries.
In recent years there has been a broadening in focus in the measurement of health beyond traditional health indicators such as mortality and morbidity, to include measures of the impact of disease and impairment on daily activities and behavior, perceived health measures and disability / functional status measures. The Quality of life (QOL) assessment is focused on humanistic element and intervention resulting from this result may lead to better overall patient well being. ${ }^{3}$ 


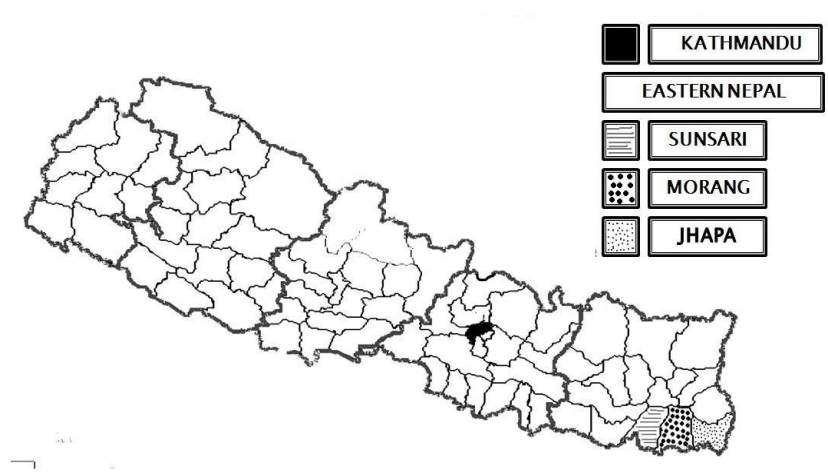

Figure 1. Map of Nepal showing study areas.

The WHO has defined quality of life as individual's perception of their position in life in the context of the culture and value systems in which they live and in relation to their goals, expectations, standards and concerns. ${ }^{3}$ The quality of life of people with HIV/AIDS is a complex constellation of disease, poverty, stigma, discrimination, and lack of treatment combined with family life, work, and social activities. HIV/AIDS affects not only the infected person, but also his or her family, community, and country. At the household level, people have loss of companionship and income. At the community and national levels, they experience loss of productivity because of absenteeism and death. ${ }^{4}$

Since 1989, a few healths related quality of life (HRQOL) instruments have been used in research with HIV infected individuals. These have documented relationships of HRQOL and HIV status, level of symptoms, use of antiretroviral drugs and use of drugs for prophylaxis of opportunistic infections separately. ${ }^{5}$ Although no such study has been published from Nepal, this study assessed the QOL among HIV positive individuals in Kathmandu valley \& Eastern region of Nepal and also compared QOL in HIV positive individuals of theses two regions.

\section{METHODS}

A case control study was done comparing quality of life of HIV positive individuals with their age and sex matched controls. The study population was taken from the districts of Sunsari, Morang, and Jhapa in Eastern region and from the Kathmandu valley of Nepal.(Fig1)

The non probability convenient sampling technique was used to select the HIV positive individuals. The investigators contacted all the local organizations working for the welfare of HIV positive individuals in Eastern region and Kathmandu valley, and most organizations helped in recruiting cases. HIV positive individuals registered with the organizations were contacted and after taking the consent, the individuals were asked to fill the questionnaire, if literate, or verbally administered if unable to read. Inclusion criteria were: 1) HIV positive persons diagnosed more than two weeks earlier, and 2) age of 18 years or older. An equal number of age and sex matched controls were taken in the community where the study was conducted. Controls were recruited by randomly approaching men and women and requesting them to participate by filling the questionnaire.

Quality of life was evaluated using the World Health Organization WHO QOL-BREF questionnaire Nepali version. ${ }^{3}$ The WHOQOL BREF consists of 26 items. Each item uses a Likert-type five-point scale. The first two items were examined separately: one which asked about the individual's overall perception of QOL and the other which asked about the individual's overall perception of his or her health. The remaining 24 items are distributed in four domains. The four domains of QOL are, (a) Physical health (seven items assessing areas such as presence of pain and discomfort, activities of daily living, dependence on medicinal substances, energy and fatigue, mobility, sleep and perceived working capacity); (b) Psychological well being (six items assessing areas such as affect, both positive and negative self concept, higher cognitive functions, body image and spirituality), (c) Social relationships (three items assessing areas such as personal relationships, social support and sexual activity) and (d) Environment (eight items assessing areas such as financial resources, freedom, physical safety and security, health and social care: quality and accessibility, physical and home environment, transport and opportunities for recreation and acquiring new information).

Domain scores were scaled in a positive direction (higher scores denote higher quality of life). The mean score of items within each domain was transformed to a 0-100 scale according to guidelines given under scoring the WHOQOL-BREF. ${ }^{3}$ Following WHOQOL- BREF instructions the assessment was discarded, where more than $20 \%$ data were missing. Where an item was missing, the mean of other items in the domain was substituted. Where more than two items were missing from a domain, the domain score was not calculated (with exception of social domain, where the domain score was calculated only if none of item was missing. ${ }^{3}$

Statistical analysis was performed using the software SPSS version 10.0. Data were expressed as mean \pm SD. The statistical significance of the values was determined using Independent-Samples T-Test for mean QOL scores between groups. Chi square test was used to compare the categorical variables. Statistical significance was accorded to a $p$-value $<0.05$.

\section{RESULTS}

\section{Characteristics of the study patients}

The study population comprised of 441 HIV positive individuals: 228 from Eastern region and 213 from Kathmandu valley. An equal number of age-sex matched controls were taken from the community. There was no significant difference $(P>0.05)$ in the mean age, sex distribution and religion of the cases and the controls. The 


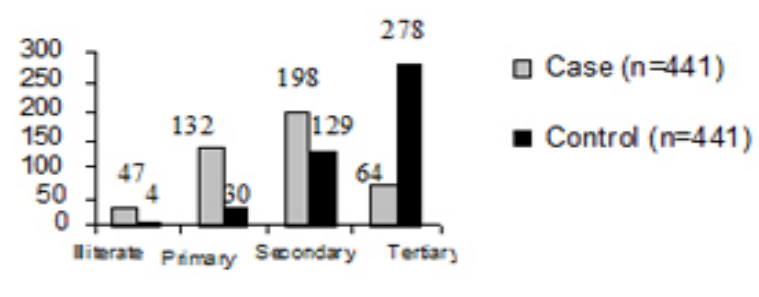

Figure 2. Educational levels of cases and controls.

mean age of cases was $29.14 \pm 5.42$ years whereas the mean age of controls was $28.23 \pm 8.17$ years. Eighty-eight percent of the subjects in all the groups were Hindu.

Most of the HIV positive individuals had received education upto secondary level whereas most of the controls had education upto tertiary level (Fig 2). HIV positive individuals had significantly lower $(\mathrm{P}<0.001) \mathrm{QOL}$ scores than the controls in the overall QOL and all the domains of life: Physical, Psychological, Social and Environmental.(Table 1)

The HIV positive individuals of Kathmandu had better overall QOL, Physical, Psychological and Environmental domains than those in Eastern region but this was significant $(P<0.001)$ only for the Physical and Environmental domain. In contrast, the HIV positives from Eastern region had better Social domain scores.(Table 2)

The HIV positive females had a significantly higher $(P<0.02)$ QOL scores than the males with respect to the Overall QOL and better perception of their health. The HIV positive males had better Psychological and Social domain scores than the females but the difference was not significant . (Table 3)

The asymptomatic HIV positive individuals had significantly higher $(\mathrm{P}<0.02) \mathrm{QOL}$ scores in the overall QOL, Physical, Psychological and Environmental domains than the symptomatic HIV positive individuals. There was no significant difference $(\mathrm{P}=0.606)$ among the symptomatic and asymptomatic HIV positives in the Social domain scores.

The HIV positive individuals were asked if they had suffered from any of the following diseases: i) Tuberculosis, ii) Shingles, iii) Oral thrush, iv) Cryptococcal meningitis, v) Pneumonia. The HIV positive individuals who had suffered from any of the above diseases had significantly lower $(\mathrm{P}<0.01)$ Overall QOL and the domains: Physical, Psychological, Social and Environmental.

Sixty-three percent of the subjects had acquired HIV through IV drug use while $37 \%$ through sexual route. The IV drug users had lower QOL scores in all aspects of life than the others but is significant $(P<0.01)$ only for the Overall QOL and Environmental domain.
Table 1. QOL Scores (HIV positive vs. Controls).

\begin{tabular}{|c|c|c|c|c|c|}
\hline \multirow[t]{2}{*}{ Domain } & \multirow[t]{2}{*}{$\begin{array}{l}\text { Case } \\
(n=441)\end{array}$} & \multirow[t]{2}{*}{$\begin{array}{l}\text { Control } \\
(n=441)\end{array}$} & \multirow[t]{2}{*}{$\begin{array}{l}p- \\
\text { value }\end{array}$} & \multicolumn{2}{|c|}{$\begin{array}{l}95 \% \text { Confi- } \\
\text { dence Interval }\end{array}$} \\
\hline & & & & Lower & Upper \\
\hline Overall QOL & $\begin{array}{l}55.42 \pm \\
16.89\end{array}$ & $\begin{array}{l}68.62 \pm \\
17.43\end{array}$ & 0.001 & -15.47 & -10.93 \\
\hline $\begin{array}{l}\text { Overall Perception } \\
\text { of Health }\end{array}$ & $\begin{array}{l}61.41 \pm \\
17.45\end{array}$ & $\begin{array}{l}70.02 \pm \\
17.38\end{array}$ & 0.001 & -10.92 & -6.32 \\
\hline Physical & $\begin{array}{l}54.59 \pm \\
13.71\end{array}$ & $\begin{array}{l}66.46 \pm \\
13.40\end{array}$ & 0.001 & -13.66 & -10.08 \\
\hline Psychological & $\begin{array}{l}52.75 \pm \\
14.19\end{array}$ & $\begin{array}{l}61.00 \pm \\
14.40\end{array}$ & 0.001 & -10.15 & -6.37 \\
\hline Social & $\begin{array}{l}55.58 \pm \\
17.54\end{array}$ & $\begin{array}{l}65.75 \pm \\
17.83\end{array}$ & 0.001 & -12.51 & -7.83 \\
\hline Environmental & $\begin{array}{l}52.05 \pm \\
12.93\end{array}$ & $\begin{array}{l}57.89 \pm \\
16.15\end{array}$ & 0.001 & -7.78 & -3.91 \\
\hline
\end{tabular}

Table 2. QOL Scores of HIV positive in (Kathmandu vs. Eastern Nepal).

\begin{tabular}{|c|c|c|c|c|c|}
\hline \multirow[t]{2}{*}{ Domain } & \multirow[t]{2}{*}{$\begin{array}{l}\text { Kathman- } \\
\text { du }(n=213)\end{array}$} & \multirow[t]{2}{*}{$\begin{array}{l}\text { Eastern Ne- } \\
\text { pal }(n=228)\end{array}$} & \multirow[t]{2}{*}{$\begin{array}{l}\mathrm{p}- \\
\text { value }\end{array}$} & \multicolumn{2}{|c|}{$\begin{array}{l}\text { 95\% Confi- } \\
\text { dence Interval }\end{array}$} \\
\hline & & & & Lower & Upper \\
\hline Overall QOL & $\begin{array}{l}55.87 \pm \\
17.96\end{array}$ & $\begin{array}{l}55.00 \pm \\
15.86\end{array}$ & 0.590 & -2.30 & 4.03 \\
\hline $\begin{array}{l}\text { Overall Percep- } \\
\text { tion of Health }\end{array}$ & $\begin{array}{l}62.63 \pm \\
17.93\end{array}$ & $\begin{array}{l}60.26 \pm \\
16.95\end{array}$ & 0.155 & -0.90 & 5.63 \\
\hline Physical & $\begin{array}{l}57.46 \pm \\
15.05\end{array}$ & $\begin{array}{l}51.96 \pm \\
11.73\end{array}$ & 0.001 & 3.04 & 8.07 \\
\hline Psychological & $\begin{array}{l}53.19 \pm \\
15.15\end{array}$ & $\begin{array}{l}52.33 \pm \\
13.26\end{array}$ & 0.524 & -1.80 & 3.52 \\
\hline Social & $\begin{array}{l}54.67 \pm \\
17.29\end{array}$ & $\begin{array}{l}56.43 \pm \\
17.76\end{array}$ & 0.292 & -5.05 & 1.52 \\
\hline Environment & $\begin{array}{l}54.21 \pm \\
14.41\end{array}$ & $\begin{array}{l}50.03 \pm \\
11.03\end{array}$ & 0.001 & 1.79 & 6.57 \\
\hline
\end{tabular}

Table 3. QOL Scores of HIV positives with respect to Sex distribution.

\begin{tabular}{|c|c|c|c|c|c|}
\hline \multirow[t]{2}{*}{ Domain } & \multirow[t]{2}{*}{$\begin{array}{l}\text { Male } \\
(n=441)\end{array}$} & \multirow[t]{2}{*}{$\begin{array}{l}\text { Female } \\
(n=441)\end{array}$} & \multirow[t]{2}{*}{$\begin{array}{l}p- \\
\text { value }\end{array}$} & \multicolumn{2}{|c|}{$\begin{array}{l}\text { 95\% Confi- } \\
\text { dence Interval }\end{array}$} \\
\hline & & & & Lower & Upper \\
\hline Overall QOL & $\begin{array}{l}53.56 \pm \\
17.20\end{array}$ & $\begin{array}{l}58.95 \pm \\
15.74\end{array}$ & 0.001 & -8.68 & -2.09 \\
\hline $\begin{array}{l}\text { Overall Perception } \\
\text { of Health }\end{array}$ & $\begin{array}{l}60-07 \pm \\
17.91\end{array}$ & $\begin{array}{l}63.95 \pm \\
16.28\end{array}$ & 0.026 & -7.30 & -0.46 \\
\hline Physical & $\begin{array}{l}54.56 \pm \\
13.90\end{array}$ & $\begin{array}{l}54.66 \pm \\
13.37\end{array}$ & 0.938 & -2.81 & 2.59 \\
\hline Psychological & $\begin{array}{l}53.46 \pm \\
15.07\end{array}$ & $\begin{array}{l}51.39 \pm \\
12.30\end{array}$ & 0.147 & -0.73 & 4.85 \\
\hline Social & $\begin{array}{l}55.96 \pm \\
18.65\end{array}$ & $\begin{array}{l}54.86 \pm \\
15.24\end{array}$ & 0.534 & -2.36 & 4.55 \\
\hline Environmental & $\begin{array}{l}50.96 \pm \\
12.51\end{array}$ & $\begin{array}{l}54.11 \pm \\
13.50\end{array}$ & 0.150 & -5.68 & -0.62 \\
\hline
\end{tabular}

QOL (Quality of Life), P Value $<0.05$ is significant 


\section{DISCUSSION}

Quality of life conveys an overall sense of well being and includes aspects such as happiness and satisfaction in life as a whole. Quality of life is often regarded as a concept that is too nebulous to be measured reliably with a structured questionnaire and is subject to too much variability across cultures and individuals to have any useful validity. The WHOQOL questionnaire is available in 2 versions: WHO QOL-100 and WHO QOL-BREF in several different languages. This questionnaire was developed cross-culturally and has been field tested in several countries around the world as an instrument for measuring the QOL. The WHOQOL project demonstrated that QOL could be conceptualized and defined in a uniform way across cultures in different centres. $^{3}$ These developments are of major significance to health care professionals, who aim not only to prevent and treat diseases but also to promote health and quality of life. ${ }^{6}$

In contrast to many other quality of life instruments, WHOQOL includes a domain on environment; this is considered necessary as environment plays a major role in determining health status, mediating disease pathogenesis and limiting or facilitating access to health care. ${ }^{6}$ We used WHO-BREF scale as it is useful in busy clinics and wards since it takes only five to eight minutes to complete. ${ }^{7}$ In this study most of the HIV positive individuals had received education up to secondary level whereas most of the controls had education up to tertiary level. This difference in education level of HIV positive individuals and controls could be explained by the fact that the HIV positive individuals had high risk behavior (IV drug use, unsafe sex, prostitution) which could have led to drop out from schools.

The HIV positive individuals had significantly lower $(P<0.001)$ QOL scores than the controls in the overall QOL and all the domains of life: Physical, Psychological, Social and Environmental.

The HIV positive individuals had an overall QOL mean score 55.42 in the scale of $0-100$. Similarly the overall QOL score of 25.8 in HIV positive individuals has been reported from India. ${ }^{6}$ This could be due to the fact that our study was community based whereas the latter study was done in hospital settings.

The HIV positives had domain scores in descending order Social (55.58), Physical (54.59), Psychological (52.75), and Environmental (52.05). The Indian study reported scores in the order Social (80.9), Psychological (27.5), Physical (17.7) and Environmental (11.65). ${ }^{6}$ This could be due to a small sample size in the latter study.

Similarly another study reported that HIV positive individuals scored significantly lower than controls on all scales $(\mathrm{P}<0.01) .{ }^{8}$ A study from US reported that patients with AIDS had worse physical functioning than those with other chronic disease (epilepsy, gastro-esophageal reflux disease, clinically localized prostrate cancer, clinical depression, and diabetes). ${ }^{9}$

The HIV positive individuals of Kathmandu had better Overall QOL, Physical, Psychological and Environmental domains than those from Eastern Nepal but this was significant $(P<0.001)$ only for the Physical and Environmental domain. This could be due to the fact that Kathmandu being the capital city has better access to health care, good support from the social service organizations and financial resources. In contrast the HIV positives from Eastern region have better Social domain scores. This may indicate that there is more social discrimination attached to this disease in Kathmandu and the HIV positives are better accepted by the society in Eastern Nepal.

The HIV positive females had a significantly higher $(P<0.02)$ QOL scores than the males with respect to the overall QOL and better perception of their health. The HIV positive males had better Psychological and Social domain scores than the females however the difference was not significant.

In contrast a study reported that HIV positive males had higher prevalence of depressive disorders than HIV negative males. ${ }^{10}$ Similarly other studies reported that HIV positive women had substantially poorer health related QOL than men with HIV. This could be due to the difference in population and the questionnaire administered. ${ }^{11,12} \mathrm{~A}$ study from the US reported that social and particularly psychological factors are important in their influence on QOL in women with HIV infection. ${ }^{13}$

The asymptomatic HIV positive individuals had significantly higher $(P<0.02)$ QOL scores in the overall QOL score and the domains Physical, Psychological and Environmental than the symptomatic. There was no significant difference $(P=0.606)$ among the symptomatic and asymptomatic HIV positives in the Social domain scores. This could be due to fact that the symptomatic HIV positives might be receiving increased attention and social support from the family or the organizations with which they were affiliated.

Physical functioning is much worse for patients with symptomatic HIV disease or who met criteria for AIDS than the asymptomatic HIV positive individuals. ${ }^{9}$ In our study the HIV positive individuals who had suffered from any of the diseases: i)Tuberculosis, ii) Shingles, iii) Oral thrush, iv) Cryptococcal meningitis, v) Pneumonia had significantly lower $(\mathrm{P}<0.01)$ Overall $\mathrm{QOL}$ and the domains: Physical, Psychological, Social and Environmental.

In a study using WHO QOL HIV questionnaire older people (>34 years) demonstrated poorer QOL on Physical domain while younger people showed poorer Environmental and Spiritual domains of well being. ${ }^{14}$ We found no such difference in our study. 


\section{CONCLUSION}

In summary, HIV positive individuals have a poorer quality of life both in Eastern region and Kathmandu valley of Nepal than the general population in all the aspects and the HIV positive females had better Overall QOL than the males. This study highlights the need for further studies to be conducted to evaluate more determinants of QOL in HIV/ AIDS. The HIV positive individuals could be divided into the various clinical categories of HIV infection and QOL score comparison could be done. A comparative assessment of QOL scores with changing CD4 counts and with institution of anti-retroviral therapy should be done.

\section{ACKNOWLEDGEMENT}

The authors would like to thank the following organizations for the help:

The WHO for giving us permission to use WHO QOL BREF questionnaire

NGOs in Eastern Nepal: Dharan Positive, Sunrise Positive (Biratnagar), Morang AIDS Prevention Society (Biratnagar), Samudayak Sewa Kendra (Ithari), Belbari Support Group, Sparsha Damak, Jhapa Plus (Birtamod), Lava Kush Ashram (Birtamod)

NGOs in Kathmandu: Nawa Kiran Plus, Kathmandu Plus, Vision Plus, Maiti Nepal, Sneha Samaj, Sparsha Nepal, Nepal plus, Sahara Plus, Blue Diamond Society

The authors appreciate the assistance of the following: Prof. G.K Singh, Mr. Dharani Dhar Baral, Dr. Ishwori Sharma Paudel, Dipesh Agrawal.

\section{REFERENCES}

1. UNAIDS/WHO AIDS Epidemic Update. Global summary of the AIDS epidemic Dec 2006: 1-96. http://data.unaids.org/Pub/ EpiReport/2006/02-Global_Summary_2006_EpiUpdate_eng.pdf

2. 2006 Report on Global AIDS epidemic. Joint United Nations Programme on HIV/AIDS; 2006: 1-51. http://www.unaids.org/en/ KnowledgeCentre/Resources/Publications/

3. WHOQOL-BREF. Introduction, administration, scoring and generic version of the assessment. Field Trial Version. Programme on mental health. WHO, Geneva 1996:1-18. http://www.who.int/mental_ health/media/en/76.pdf

4. Phaladze N, Human S, Dlamini SB, Hulela EB, Mahlubi HI, Sukati NA et al. Quality of life and concept of "living well" with HIV/AIDS in SubSaharan Africa (World health). J Nurs Scholarsch 2005;37:120-6.

5. Wolfensberger W. Let's hand up 'QOL' as a hopeless term. In: Goode D (Ed). Quality of life for persons with disabilities: International perspective and issues. Cambridge MA: Brookline Books; 1994. P. 285-321.

6. Wig N, Lekshmi R, Pal H, Ahuja V, Mittal CM, Agarwal SK. The impact of HIV/AIDS on the quality of life: A cross sectional study in north India. Indian J Med Sci 2006;60:3-12.

7. Testa MA, Simonson DC. Measuring quality of life in hypertensive patients with diabetes. Postgraduate Med J 1988;64:50-8.

8. O'Keefe EA, Wood R. The impact of HIV infection on QOL in a multiracial South African population. Qual Life Res 1996;5:275-80.

9. Hays RD, Cunningham $W E$, Sherbourne $C D$, Wislson $I B, W u A W$, Cleary PD, et al. Health-related quality of life in patients with human immunodeficiency virus infection in the United States: results from the HIV Cost and Services Utilization Study. Am J Med 2000;108:71422.

10. Lipsitz JD, Williams JB, Rabkin JG, Remien RH, Bradbury M, el Sadr $\mathrm{W}$, et al. Psychopathology in male and female intravenous drug users with and without HIV infection. Am J Psychiatry 1994;151:1662-8.

11. Kohli RM, Sane S, Kumar K, Paranjape RS, Mehendale SM. Assessment of quality of life among HIV-infected persons in Pune, India. Qual Life Res 2005;14:1641-7.

12. Mrus JM, Williams PL, Tsevat J, Cohn SE, Wu AW. Gender differences in health-related quality of life in patients with HIV/AIDS. Qual Life Res 2005;14:479-91.

13. Sowell RL, Seals BF, Moneyham L, Demi A, Cohen L, Brake S. Quality of life in HIV-infected women in the south-eastern United States. AIDS Care 1997;9:501-12.

14. WHOQOL HIV Group. WHOQOL-HIV for quality of life assessment among people living with HIV and AIDS: results from the field test. AIDS Care 2004;16:882-9. 